\title{
Caracterización de las propiedades mecánicas del tejido muscular. Una aproximación numérica utilizando poblaciones de modelos
}

\author{
Marta Sierra ${ }^{1}$, Francisco Javier Miana-Mena ${ }^{1}$, Begoña Calvo ${ }^{1}$, María Jesús Muñoz ${ }^{2}$, \\ José Felix Rodríguez ${ }^{1}$, Jorge Grasa ${ }^{1}$ \\ ${ }^{1}$ Grupo de Mecánica Aplicada y Bioingeniería (AMB) \\ ${ }^{2}$ Laboratorio de genética bioquímica de la Universidad de Zaragoza (LAGENBIO) \\ Instituto de Investigación en Ingeniería de Aragón (I3A) \\ Universidad de Zaragoza, Mariano Esquillor s/n, 50018, Zaragoza, Spain. \\ Tel. +34-976762707, e-mail: msierra@unizar.es
}

\begin{abstract}
En este estudio se caracterizó experimentalmente la contracción concéntrica del músculo Tibial Anterior (TA) de rata $(n=6)$ bajo el efecto de tres diferentes pesos (1, 2 y $3 \mathrm{~N})$. Para determinar una serie de parámetros característicos de un modelo computacional del tejido, se generó una gran población de simulaciones numéricas considerando una dispersión preestablecida de dichos parámetros. Esa población permitió ajustar estadísticamente las propiedades mecánicas considerando la dispersión de los resultados experimentales.
\end{abstract}

\section{Introducción}

La simulación computacional se ha convertido en una potente herramienta para entender el comportamiento de los tejidos biológicos como el tejido músculo esquelético [1,2].

En este trabajo se ha caracterizado en primer lugar la contracción concéntrica ex vivo del TA de rata para seis animales y bajo la acción de diferentes cargas externas de 1,2 y 3 N. Posteriormente, y utilizando estos resultados experimentales, se ha desarrollado un modelo computacional del tejido que ajusta sus propiedades características discriminando los resultados de una población de resultados numéricos que no se encuentren dentro del rango de variación de la respuesta real del tejido.

\section{Material y Métodos}

Para el desarrollo experimental_se han utilizado 6 ratas Wistar macho de dos meses de edad con pesos de $313 \pm 81,14 \mathrm{~g}$. Los animales fueron suministrados por Laboratorios Harlan y se mantuvieron de acuerdo a la legislación vigente en experimentación animal. Todos los experimentos han sido aprobados por el Comité Ético de la Universidad de Zaragoza para el uso de animales de experimentación.
Los animales se anestesiaron con una inyección intraperitoneal de pentobarbital sódico $(30 \mathrm{mg} / \mathrm{kg}$ ) y la disección del músculo se realizó como se describe en [1]. Tras la disección, se fijó un hilo quirúrgico en la zona de transición entre el músculo y el tendón distal, dejando un cabo largo. Se colocó un electrodo en el nervio ciático para provocar las contracciones musculares. Los animales fueron colocados en una plataforma de metacrilato diseñada por los autores.

El músculo TA se colocó verticalmente y el extremo del hilo fue pasado por dos poleas para conectar de esta forma las diferentes cargas, que permanecían apoyadas en una superficie plana. El estímulo eléctrico aplicado al animal a través del nervio ciático se generó utilizando el generador de señal CIBERTEC CS-20 (8V, 90Hz y 10ms). La estimulación se aplicaba durante un segundo con cada carga externa. Para cada carga (1, 2 y 3 N) se realizaron tres repeticiones con periodos de descanso de 6 minutos entre contracciones. Las contracciones fueron registradas con un sistema de cámaras LAVISION. Después de cada experimento los animales fueron eutanasiados.

El comportamiento del tejido se ha formulado bajo las hipótesis de la mecánica del medio continuo en grandes deformaciones con una formulación hiperelástica transversalmente isótropa. Esta formulación incorpora dos familias de fibras asociadas al comportamiento pasivo (fibras de colágeno) y al comportamiento activo (fibras musculares). La función densidad de energía de deformación puede escribirse como [3]:

$$
\Psi=\Psi_{\mathrm{vol}}(J)+\bar{\Psi}_{\mathrm{p}}\left(\bar{I}_{1}, \bar{I}_{2}, \bar{I}_{4}\right)+f_{\lambda} f_{\mathrm{v}} f_{\text {train }} \bar{\Psi}_{\mathrm{a}}^{\prime}\left(\bar{J}_{4}\right)
$$

Esta función se representa a partir de una parte volumétrica $\Psi_{\text {vol }}$ y una parte que no implica cambio de volumen en la que se distinga la energía asociada al comportamiento pasivo $\Psi_{\mathrm{p}} \mathrm{y}$ al activo $\Psi_{\mathrm{a}}$. Estas 
funciones dependen a su vez de diferentes invariantes $\left(\mathrm{I}_{1}, \mathrm{I}_{2}, \mathrm{I}_{4}\right.$ y $\left.\mathrm{J}_{4}\right)$ y de funciones que caracterizan el comportamiento del músculo en su dependencia con su alargamiento $\left(\mathrm{f}_{\lambda}\right)$, la amplitud del estímulo $\left(\mathrm{f}_{\mathrm{V}}\right)$ y la frecuencia del mismo $\left(\mathrm{f}_{\text {train }}\right)$.

\section{Resultados}

El sistema de cámaras permitió la medición del acortamiento del músculo ( $\lambda=$ longitud final / longitud inicial), gracias al registro de 5 segundos durante la contracción. El músculo registra la máxima deformación a los 0.4 segundos desde su activación. El acortamiento máximo, $0.71 \pm 0.01$, se obtuvo para $1 \mathrm{~N}$. Para $2 \mathrm{~N}$, se obtuvo un acortamiendo de $0.81 \pm 0.06$ mientras que para $3 \mathrm{~N}$ la contracción máxima fue $0.85 \pm 0.03$. La Figura 2 muestra en rojo los resultados de las contracciones obtenidas por los músculos reales para una carga de $1 \mathrm{~N}$.

Estableciendo funciones de distribución uniformes en torno a unos rangos probables para los parámetros que definen el comportamiento pasivo y activo se construyo una muestra modelos $(n=10000)$ para cada peso que se cálculo utilizando la aplicación ABAQUS. La población completa de resultados se muestra en la Figura 2 en negro para la evolución del alargamiento frente al tiempo de la contracción. Los resultados de esta población que se encuentran dentro de los límites establecidos por los resultados experimentales se representan en color azul.

\section{Conclusiones}

El protocolo experimental propuesto establece una herramienta excepcional para el desarrollo de simulaciones realistas del músculo esquelético a partir del método de elementos finitos. Además, el modelo de comportamiento en 3D desarrollado permite calcular las propiedades del músculo teniendo en cuenta diferentes variables como la orientación de las fibras, lo que lo convierte en una herramienta fundamental para el estudio del comportamiento del músculo esquelético.
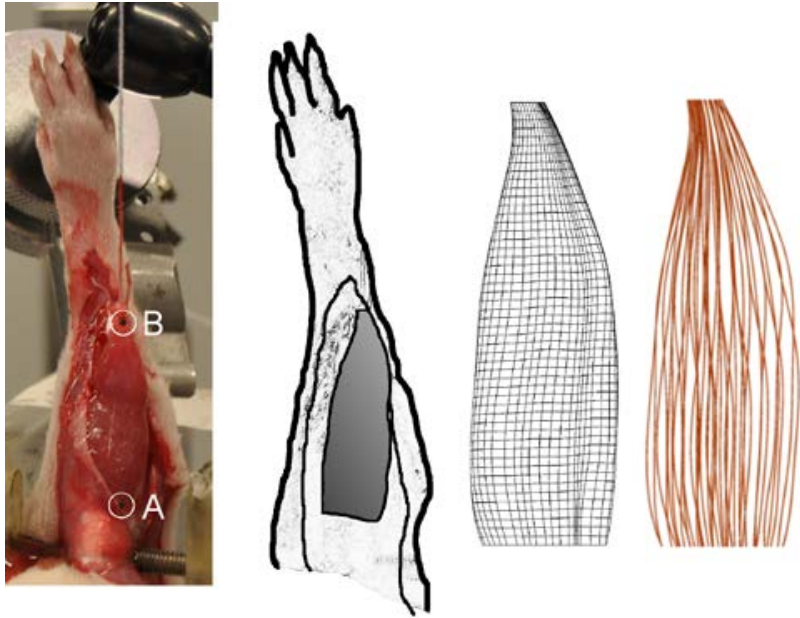

Figura 1. Músculo TA con las marcas de referencia para el cálculo del acortamiento. Malla de elementos finitos del tejido junto con las direcciones de las fibras musculares.

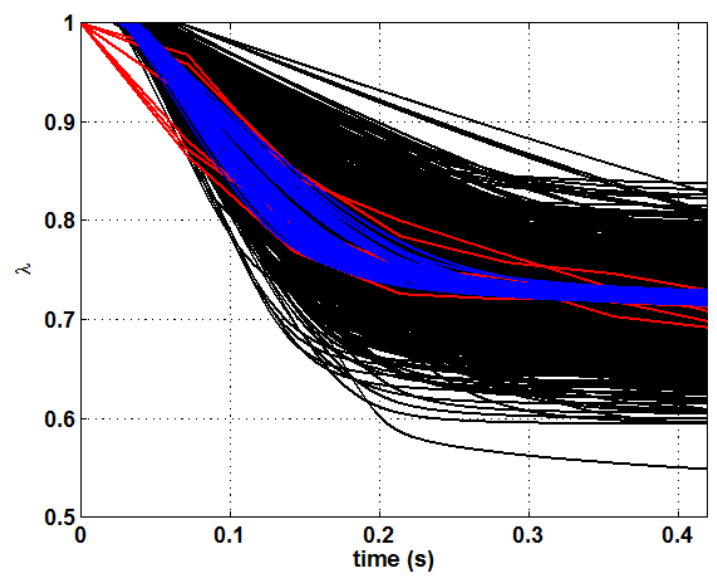

Figura 2. Evolución de la contracción del tejido (alargamiento) a lo largo del tiempo de la contracción para una carga de $1 \mathrm{~N}$. En rojo los resultados experimentales, en negro la población de resultados numéricos y en azul los resultados numéricos dentro del rango de resultados experimentales.

\section{Referencias}

[1]. GRASA J., SIERRA M., MUÑOZ M.J., SOTERAS F., OSTA R., CALVO B. and MIANA-MENA F.J. On simulating sustained isometric muscle fatigue: a phenomenological model considering different fiber metabolisms. Biomechanics and Modeling in Mechanobiology. 2014, 13(6), 1373-1385.

[2]. GRASA J., RAMIREZ A., OSTA R., MUÑOZ M. J., SOTERAS F. and CALVO B. A 3D active-passive numerical skeletal muscle model incorporating initial tissue strains. Validation with experimental results on rat tibialis anterior muscle. Biomechanics and Modeling in Mechanobiology. 2011, 10(5),779-787.

[3]. HERNÁNDEZ-GASCÓN B., GRASA J., CALVO B. and RODRÍGUEZ F.J. A 3D electro-mechanical continuum model for simulating skeletal muscle contraction. Journal of Theoretical Biology. 2013, 335: 108-118. 